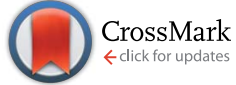

Cite this: RSC Adv., 2015, 5, 67115

Received 22nd April 2015 Accepted 29th July 2015

DOI: $10.1039 / \mathrm{c} 5 \mathrm{ra0} 07298 \mathrm{k}$

www.rsc.org/advances

\section{Electrochemical detection of a pathogenic Escherichia coli specific DNA sequence based on a graphene oxide-chitosan composite decorated with nickel ferrite nanoparticles $\uparrow$}

\begin{abstract}
Ida Tiwari, ${ }^{\star a}$ Monali Singh,,$^{\mathrm{a}}$ Chandra Mouli Pandey $\ddagger^{\mathrm{ab}}$ and Gajjala Sumana
In this report, an electrochemical genosensor has been fabricated for Escherichia coli O157:H7 (E. coli) detection using a graphene oxide-nickel ferrite-chitosan (GO/NiF/ch) nanocomposite film as the sensing platform. The prepared GO/NiF/ch nanocomposite was characterized by scanning electron microscopy, transmission electron microscopy, Raman spectroscopy, Fourier transform infrared spectroscopy and thermo-gravimetric analysis. Nucleic acid hybridization technique was employed for the detection of a specific sequence of $\mathrm{E}$. coli. The hybridization between the complementary DNA and probe DNA was investigated by differential pulse voltammetry (DPV) using methylene blue as redox indicator. The fabricated biosensor exhibits a linear response to complementary DNA in the concentration range of $10^{-6}$ to $10^{-16} \mathrm{M}$ with a detection limit of $1 \times 10^{-16} \mathrm{M}$.
\end{abstract}

\section{Introduction}

Escherichia coli O157:H7 (E. coli) is an enterohemorrhagic serotype of the bacterium Escherichia coli whose infection may lead to hemorrhagic diarrhea and kidney failure. ${ }^{1} E$. coli infection is acquired by consuming foods containing the bacteria such as lettuce, alfalfa sprouts, salami, unpasteurized milk, juice and cider. Various methods are available for detection of the pathogen like culture and colony counting method. ${ }^{2-4}$ But these traditional methods are excessively time-consuming and give ambiguous results. The current methods involve enriching the culture by growth for a specific time period followed by separation and identification using an immunological approach $^{5,6}$ or the use of polymerase chain reaction of a unique and identifying gene. ${ }^{7,8}$ However, these methods demand labeled antibodies, pre-separation, or pre-enrichment, which make them costly and complicated. To overcome these problems, there is an urgent need for a rapid, simple, sensitive and cost effective method. That's why, as alternatives to the above mentioned methods, biosensors have been explored for pathogenic bacteria detection in recent years. Because of its high sensitivity, low cost, rapid response, small dimensions (portability) and low manpower requirements, biosensors based on

\footnotetext{
${ }^{a}$ Department of Chemistry, Faculty of Science, Banaras Hindu University, Varanasi-221005, India. E-mail: idatiwari_2001@rediffmail.com

${ }^{b}$ Biomedical Instrumentation Section, CSIR-National Physical Laboratory, New Delhi110012, India

$\dagger$ Electronic supplementary information (ESI) available. See DOI: 10.1039/c5ra07298k

\$ These authors contributed equally.
}

electrochemical transduction are preferred for detection of $E$. coli. DNA electrochemical biosensors based on the nucleic acid hybridization technique is becoming attractive day by day in biology for the detection and analysis of specific DNA sequences and treatment of pathogenic diseases. In this context, Wang et al. fabricated genosensor based on DNA hybridization using Au/MWCNTs nanocomposites. ${ }^{9}$ Tak et al. designed ZnO nanostructure based electrochemical DNA biosensor for bacterial meningitis detection. ${ }^{10}$ An electrochemical DNA sensor based on multi-walled carbon nanotubes- $\mathrm{SnO}_{2}-$ chitosan nanocomposite was developed by Yang et al. ${ }^{\mathbf{1 1}}$ An electrochemical genosensor based on modified octadecanethiol self-assembled monolayer for E. coli detection was designed by Pandey et al. ${ }^{\mathbf{1 2}}$

In the past decade, graphene, has attracted great interest in the field of electrochemistry because of its unique physical and chemical properties. ${ }^{13}$ It is one-atom-thick planar sheet of $\mathrm{sp}^{2}$ bonded carbon atoms densely packed in a honeycomb crystal lattice, possessing high surface area, excellent thermal conductivity, electric conductivity, catalytic properties and strong mechanical strength. ${ }^{\mathbf{1 4}}$ Graphene oxide (GO) which is graphene with its surface modified by hydroxyl and carboxyl groups has been used to fabricate DNA sensors with high sensitivity due to its excellent electrocatalytic properties as well as conductivity and sensing applications. ${ }^{15}$ Moreover, the high specific surface area of graphene is helpful in providing high loading concentration of pDNA on it. ${ }^{16}$ Various reports are available using GO for the construction of genosensor. Ali et al. developed a biosensor for sensitive detection of Amelogenin gene using reduced graphene oxide based on nucleic acid hybridization. ${ }^{17}$ A novel DNA biosensor based on GO and 
polyaniline nanowires was fabricated by Yang and his coworkers. ${ }^{18}$ Zainudin et al. designed an impedimetric DNA biosensor based on graphene nanosheets for the detection of $E$. coli. ${ }^{19}$ Zeng et al. developed a facile interface for construction of DNA-based electrochemical biosensor using graphene and CdS nanocomposite for the determination of phenformin. ${ }^{20}$ An electrochemical deoxyribonucleic acid biosensor based on carboxyl functionalized graphene oxide and poly lysine modified electrode for the detection of TLH gene sequence related to Vibrio paraheamolyticus was fabricated by Sun et al. ${ }^{\mathbf{2 1}}$

With development in nanotechnology, nanomaterials have received great attention for sensor design to improve sensing performance. Recently, nanoparticles have been extensively used in DNA hybridization sensing for amplification of hybridization due to their effective catalytic properties, biocompatibility and non-toxicity. Anqi Shi and his coworkers developed a sensitive electrochemical DNA biosensor based on nucleic acid hybridization technique using gold nanomaterial and graphene composite as electrocatalyst. ${ }^{22}$ An electrochemical sensor for detection of DNA hybridization based on silver-enhanced gold nanoparticle label was fabricated by Hong et $a .^{23} \mathrm{Xu}$ et al. prepared CuS-graphene-Au nanoparticles composite to design an electrochemical DNA sensor based on nucleic acid hybridization. ${ }^{24}$

In nanoparticles, spinel ferrites $\left(\mathrm{MFe}_{2} \mathrm{O}_{4} ; \mathrm{M}=\mathrm{Fe}, \mathrm{Co}, \mathrm{Ni}\right.$, $\mathrm{Mn}, \mathrm{Zn}$, etc.) have recently attracted a great deal of attention due to their unique electrical and magnetic properties. ${ }^{25}$ Among them, nickel ferrite $\left(\mathrm{NiFe}_{2} \mathrm{O}_{4}\right)$ is one of the most important spinel ferrites due to their good biocompatibility, strong super paramagnetic property, low toxicity, easy preparation and high adsorption ability. ${ }^{26}$ Moreover, $\mathrm{NiFe}_{2} \mathrm{O}_{4}$ has high effective surface area, less resistance for mass transfer, rapid rate in electrocatalysis, and convenient control over the electrode. ${ }^{27,28}$ Hence, decoration of $\mathrm{GO}$ with $\mathrm{NiFe}_{2} \mathrm{O}_{4}$ nanoparticles improve electrochemical properties of the hybrid material due to the combination of the excellent electrical conductivity of graphene and the outstanding magnetic properties of nanoparticles. However, until now, very few reports are available concerning the $\mathrm{NiFe}_{2} \mathrm{O}_{4}$ graphene nanocomposites. ${ }^{29,30}$ Chitosan, a natural polymer, is used to disperse nanomaterials due to its admirable properties such as non-toxicity, biodegradability, and good compatibility. ${ }^{31}$

In this work, we report a new electrochemical sensing platform $(\mathrm{GO} / \mathrm{NiF} / \mathrm{ch})$ with excellent electrocatalytic activity which was used to fabricate a genosensor by immobilizing probe sequence specific to $E$. coli and then incorporating complementary target sequence specific to that of probe DNA. The hybridization between $E$. coli pDNA and cDNA on GO/NiF/ch modified electrode was detected with DPV measurement in the presence of MB as the indicator. The approach was further utilized to determine the concentration of $E$. coli. To the best of our knowledge, this report is first time showing the application of $\mathrm{GO} / \mathrm{NiF} / \mathrm{ch}$ nanocomposite for the fabrication of electrochemical DNA biosensor for rapid detection of $E$. coli with high sensitivity and selectivity using DPV by monitoring the oxidation of redox indicator methylene blue (MB).

\section{Materials and methods}

\subsection{Material and chemicals}

Graphite powder, 1-ethyl-(dimethylaminopropyl) carbodiimide (EDC), $N$-hydroxysuccinimide (NHS), nickel(II) nitrate hexahydrate $\mathrm{Ni}\left(\mathrm{NO}_{3}\right)_{2} \cdot 6 \mathrm{H}_{2} \mathrm{O}$, iron(III) nitrate hexahydrate $\mathrm{Fe}\left(\mathrm{NO}_{3}\right)_{3} \cdot 9 \mathrm{H}_{2} \mathrm{O}$ and chitosan (MW 15 000-20 000) were of analytical grade and purchased from Sigma-Aldrich. The probe sequence (17 mer.) specific to $E$. coli has been identified from the $16 \mathrm{~s}$ rRNA coding region of the $E$. coli genome, complementary, non-complementary and one-base mismatch target sequences have been procured from Sigma Aldrich, Milwaukee, USA. Sequences of oligonucleotide probes are listed as follows:

Probe I: probe DNA (pDNA): amine- $5^{\prime}$-GGT CCG CTT GCT CTC GC-3'.

Probe II: complementary DNA (cDNA): $5^{\prime}$-GCG AGA GCA AGC GGA CC- $3^{\prime}$.

Probe III: non-complementary DNA: $5^{\prime}$-CTA GTC GTA TAG TAG GC-3'.

Probe IV: one-base mismatch DNA: $5^{\prime}$-GCG AGA GAA AGC GGA CC-3'.

The solution of oligonucleotide are prepared in Tris-EDTA buffer (1 M Tris-HCl, 0.5 M EDTA) of $\mathrm{pH} 8.0$ and stored at $-20{ }^{\circ} \mathrm{C}$ prior to use.

\subsection{Apparatus}

$\mathrm{X}$-ray powder diffraction analysis (XRD) was performed using D8 Advance/Discover Bruker. Germany, Diffractometer with CuKa. The morphological investigations of $\mathrm{GO} / \mathrm{NiF} / \mathrm{ch}$ have been carried out using transmission electron microscopic (Tecnai20G2 $200 \mathrm{kV}$ ) instrument. The scanning electron microscopy images have been recorded using a JEOLJSM-6700F fieldemitting scanning electron microscope (FESEM, $15 \mathrm{kV}$ ). Fourier transform infra-red (FT-IR) spectroscopy measurements have been carried out using $\mathrm{KBr}$ pellets on Varian 3100. The electrochemical measurements were performed with an Auto lab potentiostat/galvanostat (Eco Chemie, Netherlands) using a three-electrode cell using ITO as working electrode, platinum as auxiliary electrode and $\mathrm{Ag} / \mathrm{AgCl}$ as reference electrode in phosphate buffer (PBS, $100 \mathrm{mM}, \mathrm{pH} 7.4,0.9 \% \mathrm{NaCl}$ ) containing 5 $\mathrm{mM}\left[\mathrm{Fe}(\mathrm{CN})_{6}\right]^{3-/ 4-}$.

\subsection{Synthesis of $\mathrm{rGO} / \mathrm{NiFe}_{2} \mathrm{O}_{4}$ composite}

GO was prepared by chemical oxidation and exfoliation of natural graphite according to the modified Hummers method. ${ }^{32}$ $\mathrm{GO} / \mathrm{NiFe}_{2} \mathrm{O}_{4}$ composite was prepared hydrothermally as follows: $100 \mathrm{mg}$ GO was dispersed in $100 \mathrm{~mL} \mathrm{H}_{2} \mathrm{O}$ and stirred for $12 \mathrm{~h}$ to form a homogeneous aqueous dispersion. Then $0.3 \mathrm{~g} \mathrm{Ni}\left(\mathrm{NO}_{3}\right)_{2}$ and $0.6 \mathrm{~g} \mathrm{Fe}\left(\mathrm{NO}_{3}\right)_{3}$ were added into the GO dispersion followed by stirring at room temperature. $\mathrm{NH}_{3}$ solution was added to the solution slowly and simultaneously to adjust the $\mathrm{pH}$ to 10 . Then the mixture was transferred into a $100 \mathrm{~mL}$ teflon-lined autoclave and maintained at $180{ }^{\circ} \mathrm{C}$ for $24 \mathrm{~h}$ for crystallizing. The product was washed with distilled water several times and dried at $50{ }^{\circ} \mathrm{C}$ for $24 \mathrm{~h}^{30} \mathrm{GO}$ has proven to be an effective matrix for the adhesion of nanostructures due to the rich content of oxide 
functional groups on the basal planes and edges of the 2-D material. Positively charged $\mathrm{Ni}^{2+}$ and $\mathrm{Fe}^{3+}$ are attracted to negatively charged electron cloud surrounding the oxygen atoms of the GO sheets due to electrostatic interaction and get attached to it forming a composite.

\subsection{Preparation of graphene oxide-nickel ferrite-chitosan nanocomposite}

$10 \mathrm{mg}$ of chitosan was dispersed in $10 \mathrm{~mL}$ sodium acetateacetic acid solution (0.2 $\mathrm{M}, \mathrm{pH} 4.6)$ and ultrasonicated for 1 hour to get a suspension. Further, $1 \mathrm{mg}$ of $\mathrm{GO} / \mathrm{NiFe}_{2} \mathrm{O}_{4}$ hybrid was added in the chitosan solution. Then $0.5 \mathrm{~mL}(0.5 \% \mathrm{w} / \mathrm{v})$ EDC was added in this solution followed by ultrasonication of the solution for 30 minutes which results in nanocomposite formation. ${ }^{33}$

\subsection{Electrophoretic deposition of $\mathrm{GO} / \mathrm{NiF} / \mathrm{ch}$ nanocomposite onto ITO electrode}

For the electrophoretic deposition of $\mathrm{GO} / \mathrm{NiF} / \mathrm{ch}$ nanocomposite, the prepared nanocomposite was diluted with ethanol in a $1: 3$ ratio. This solution was connected with potentiostat using a two-electrode system (a pre-hydrolyzed ITO electrode acting as cathode with parallel-placed platinum acting as the anode) and DC potential of $15 \mathrm{~V}$ was applied for 2 minutes. Due to the presence of $\mathrm{NH}_{3}{ }^{+}$in chitosan and metal ions attached on graphene surface, the composite is positively charged, hence migrated towards cathode (ITO electrodes) and gets deposited on it.

\subsection{Fabrication of nucleic acid-functionalized $\mathrm{GO} / \mathrm{NiF} / \mathrm{ch} /$ ITO electrode}

$20 \mu \mathrm{L}$ of pDNA was immobilized on the $\mathrm{GO} / \mathrm{NiF} / \mathrm{ch} / \mathrm{ITO}$ electrode surface, via the formation of $\mathrm{C}-\mathrm{N}$ bond by using the homo-bifunctional cross-linker, glutaraldehye $(0.1 \% \mathrm{v} / \mathrm{v} ; 4 \mathrm{~h})$, which bonds covalently to the primary amine groups of chitosan at one end, and to an amino group at the $5^{\prime}$-terminal of a pDNA at the other end. ${ }^{15}$ Hybridization was performed by incubating the prepared pDNA/GO/NiF/ch/ITO bioelectrodes in the various concentration of complementary target DNA solution for 30 minutes using methylene blue as indicator and the corresponding change in current was measured by DPV which was further utilized for detection of $E$. coli. ${ }^{22}$ The different steps involved in the fabrication of pDNA/GO/NiF/ch/ITO electrode have been shown in the Fig. 1 .

\subsection{Electrochemical measurements}

For electrochemical measurements, pDNA/GO/NiF/ch/ITO bioelectrodes were incubated with target DNA (complementary, non-complementary and one-base mismatch DNA sequences) for about $60 \mathrm{~s}$ at $25^{\circ} \mathrm{C}$ to achieve hybridization in presence of methylene blue $(20 \mu \mathrm{M})$ at $+0.1 \mathrm{~V}$ for $10 \mathrm{~s}$ and washed with phosphate buffer to remove unbound target molecules. Finally,
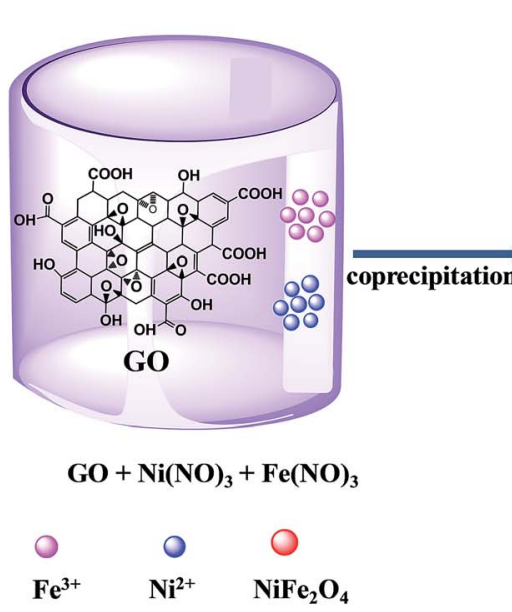

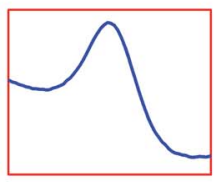

Electrochemica detection

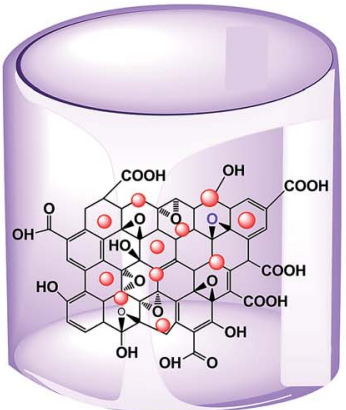

$\mathrm{GO} / \mathrm{NiFe}_{2} \mathrm{O}_{4}$
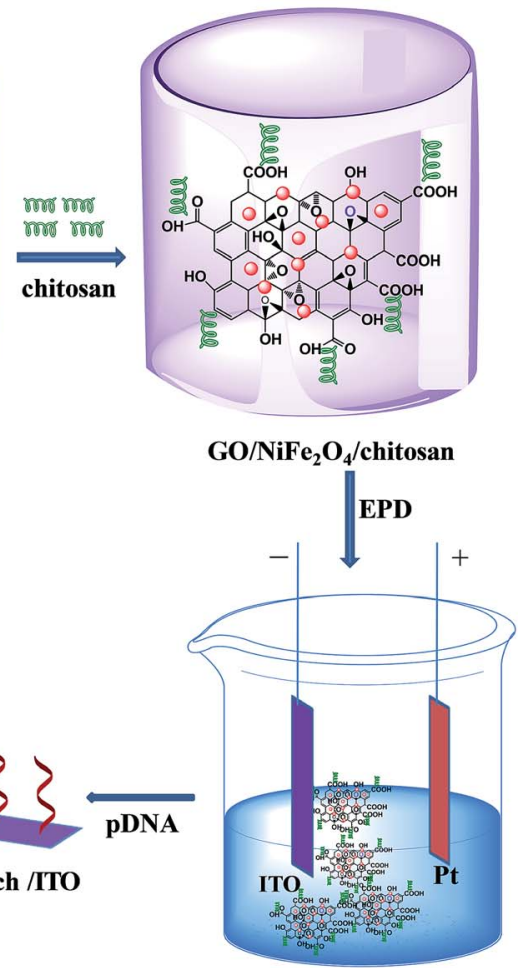

GO/NiF/ch /ITO

Fig. 1 Schematic illustration for the preparation of GO/NiF/ch nanocomposite, EPD of nanocomposite onto ITO electrode and its application for electrochemical detection of $E$. coli. 
DPV technique was used to investigate the hybridization event. $^{12}$

\section{Results and discussion}

\subsection{X-ray powder diffraction (XRD) analysis}

Fig. 2A shows the XRD patterns of graphene which shows a strong peak at $10.3^{\circ}$ corresponding to the (002) reflection of graphene oxide inter-planar spacing of $0.87 \mathrm{~nm}^{34,35}$ Two humps are observed at $2 \theta$ values of $20.3^{\circ}$ and $26.5^{\circ}$ respectively which reveal the presence of a few layers of graphene. Fig. 2B shows the XRD pattern of $\mathrm{NiFe}_{2} \mathrm{O}_{4}$. It can be seen that almost all the diffraction peaks are observed at the $2 \theta$ values of $30.2^{\circ}$, $35.3^{\circ}, 42.8^{\circ}$, and $62.4^{\circ}$ which can be assigned to (111), (311), (222), (440) crystal planes of spinel $\mathrm{NiFe}_{2} \mathrm{O}_{4}$ respectively. These diffraction lines confirm the formation of $\mathrm{NiFe}_{2} \mathrm{O}_{4}$. Fig. $2 \mathrm{C}$ shows the XRD pattern of $\mathrm{GO} / \mathrm{NiF} / \mathrm{ch}$ nanocomposite which is very much similar to $\mathrm{NiFe}_{2} \mathrm{O}_{4}$ revealing that the orientation of nanoparticles has not changed in the composite. It can be observed that there is no typical diffraction peak of GO in the
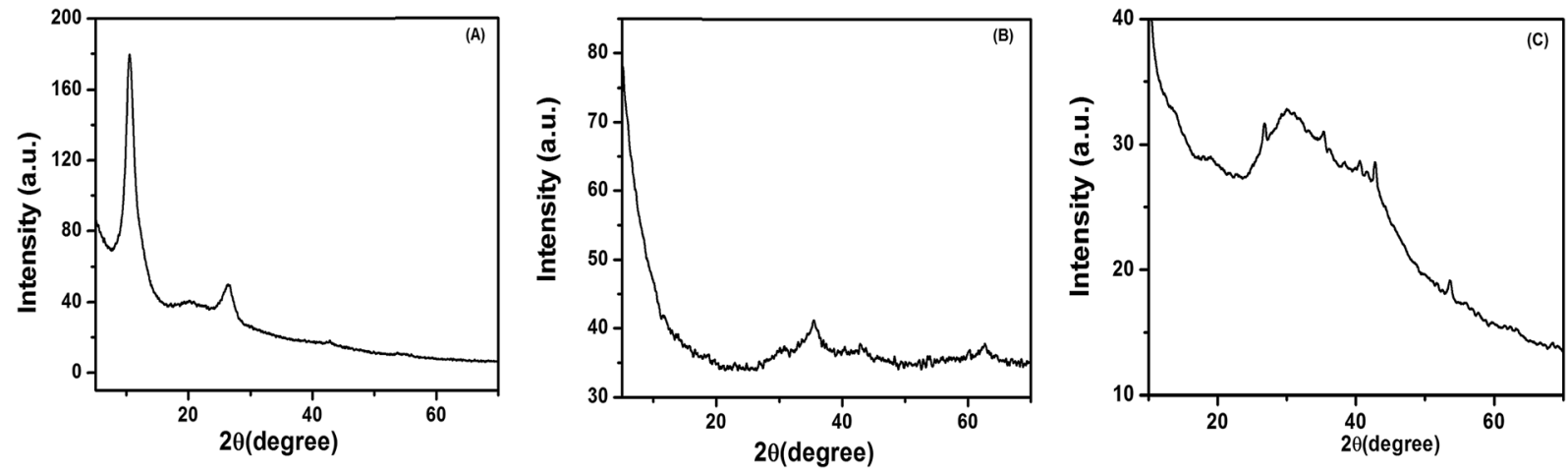

Fig. 2 XRD pattern of (A) $\mathrm{GO}$, (B) $\mathrm{NiFe}_{2} \mathrm{O}_{4}$ nanoparticles, (C) GO/NiF/ch nanocomposite.
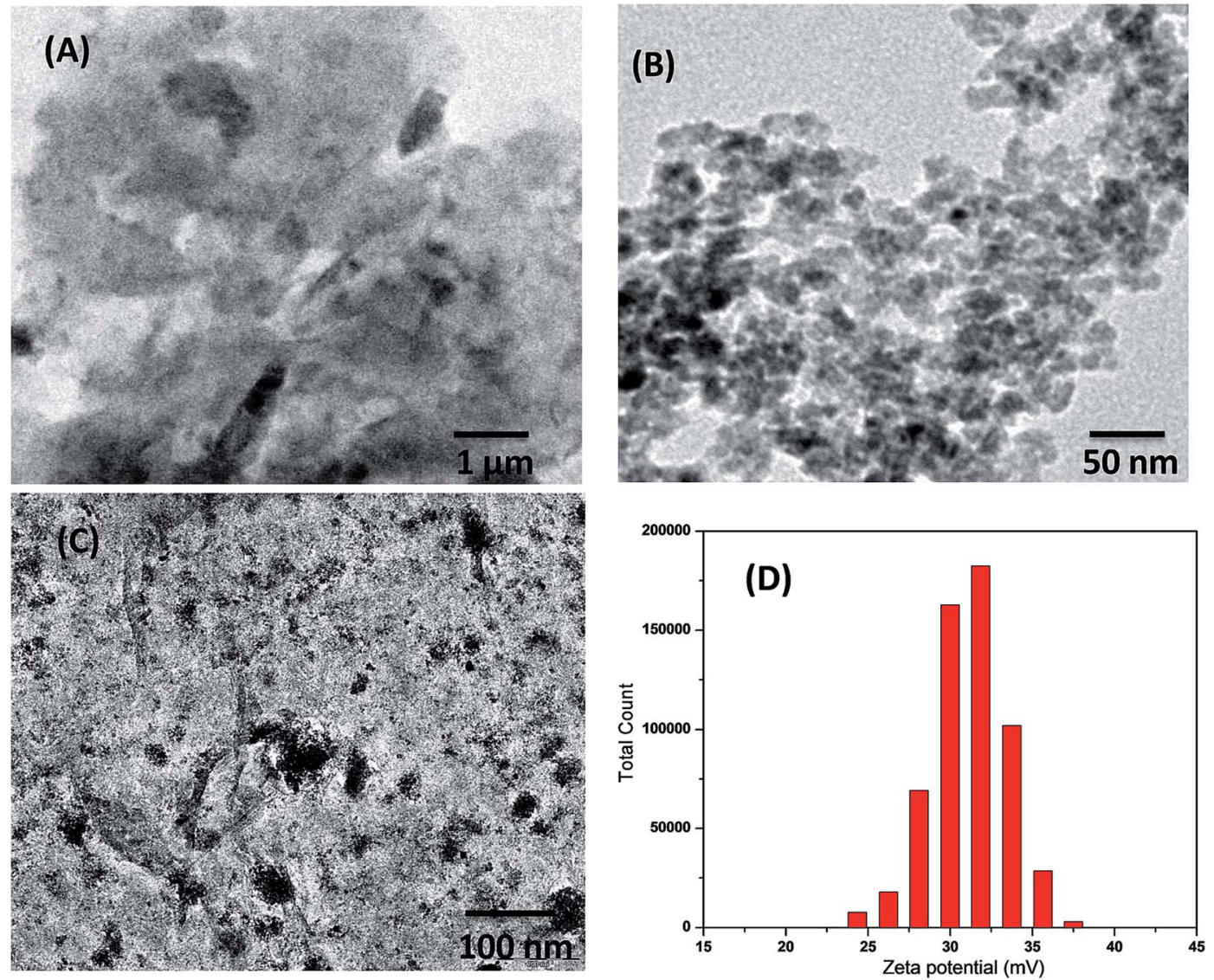

Fig. 3 Transmission electron micrograph (TEM) images of (A) GO, (B) $\mathrm{NiFe}_{2} \mathrm{O}_{4}$ nanoparticles, (C) GO/NiF/ch nanocomposite, (D) zeta potential of $\mathrm{GO} / \mathrm{NiF} / \mathrm{ch}$ nanocomposite at $\mathrm{pH} 4$. 
XRD pattern for $\mathrm{GO} / \mathrm{NiF} / \mathrm{ch}$ which indicates that $\mathrm{GO}$ has exfoliated to a large extent and the nanoparticles are deposited on it revealing the formation of nanocomposite.

\subsection{Transmission electron microscopic (TEM) studies}

The morphology of $\mathrm{GO} / \mathrm{NiF} / \mathrm{ch}$ nanocomposite was studied using TEM. Fig. 3A shows the TEM image of graphene exhibiting wrinkles and flake like structure confirming the formation of graphene. Fig. 3B shows the TEM image of $\mathrm{NiFe}_{2} \mathrm{O}_{4}$ nanoparticles which exhibits sphere like structure having size $50 \mathrm{~nm}$. Fig. 3C shows the TEM image of $\mathrm{GO} / \mathrm{NiF} / \mathrm{ch}$ nanocomposites. It can be observed that when the nanoparticles were deposited on graphene sheets they were uniformly distributed and entrapped inside the GO matrix forming an interconnected hybrid network. The diameter of nanoparticles was found to be $200 \mathrm{~nm}$ implying that most of the particles are deposited together showing particle size $200 \mathrm{~nm} \cdot{ }^{30}$ Here, GO membrane serves as a template, on top of which $\mathrm{Ni}^{2+}$ and $\mathrm{Fe}^{3+}$ metal nanoparticles are generated. The oxygen rich sites of graphene oxide behave as receptor sites for $\mathrm{Ni}^{2+}$ and $\mathrm{Fe}^{3+}$, and co-precipitation of $\mathrm{Ni}^{2+}$ and $\mathrm{Fe}^{3+}$ occurs in the area with an abundance of oxygen-containing functional groups on the GO sheets, preventing the aggregation of $\mathrm{NiFe}_{2} \mathrm{O}_{4}$ nanoparticles. ${ }^{29}$ The incorporation of nanoparticles into the graphene sheets prevents the agglomeration of nanoparticles and privileges the nucleation over growth and this combined effect led to the good particle density and monodispersity observed in the $\mathrm{GO} / \mathrm{NiF} / \mathrm{ch}$ nanocomposite. To investigate the stability of the particle, zeta potential measurements have been performed. It was found that $\mathrm{GO} / \mathrm{NiF} / \mathrm{ch}$ nanocomposite is positively charged with a zeta potential of about $28.4 \mathrm{mV}$ at the $\mathrm{pH}$ value of 4.0 , revealing that the composite is stable at this $\mathrm{pH}$ (Fig. 3D).

\subsection{Scanning electron microscopic (SEM) studies}

Fig. 4A shows the SEM image of GO/ch deposited onto ITO electrode in which thin wrinkles and flaky structure can be observed, which confirms the layered structure of graphene sheet. It can be found that the graphene film exhibits uniform morphology over large areas with numerous wrinkles on the surface, which greatly increases the surface area. ${ }^{17}$ Fig. $4 \mathrm{~B}$ shows SEM image of $\mathrm{GO} / \mathrm{NiF} / \mathrm{ch}$ on ITO electrode in which some spherical structures are observed which are distributed over the graphene/ch matrix. These spherical structures are $\mathrm{NiFe}_{2} \mathrm{O}_{4}$ nanoparticles which are well distributed over graphene-chitosan matrix but there is no change in the morphology of the GO. Fig. 4C shows the SEM image of pDNA/GO/NiF/ch/ITO. It was observed that pDNA is well immobilized on the graphene surface decorated with $\mathrm{NiFe}_{2} \mathrm{O}_{4}$ nanoparticles. The use of nanoparticles greatly increased the quantity of immobilized DNA on the electrode and effectively amplified the amperometric signal. ${ }^{36}$ Also, the energy-dispersive X-ray spectroscopy (EDS) analysis supports the formation of $\mathrm{GO} / \mathrm{NiF} / \mathrm{ch}$ nanocomposite (Fig. 4D).

\subsection{FT-IR studies}

The formation of $\mathrm{GO} / \mathrm{NiF} / \mathrm{ch}$ nanocomposite was further investigated by FTIR spectra (Fig. 5). Fig. 5(i)Fig. 5(ii) shows FTIR of GO in which a peak is observed at $3352 \mathrm{~cm}^{-1}$ which is attributed to $\mathrm{O}-\mathrm{H}$ stretching vibration, the peak at $1623 \mathrm{~cm}^{-1}$ is assigned to $\mathrm{C}-\mathrm{O}$ stretching vibration, the peak at $1469 \mathrm{~cm}^{-1}$
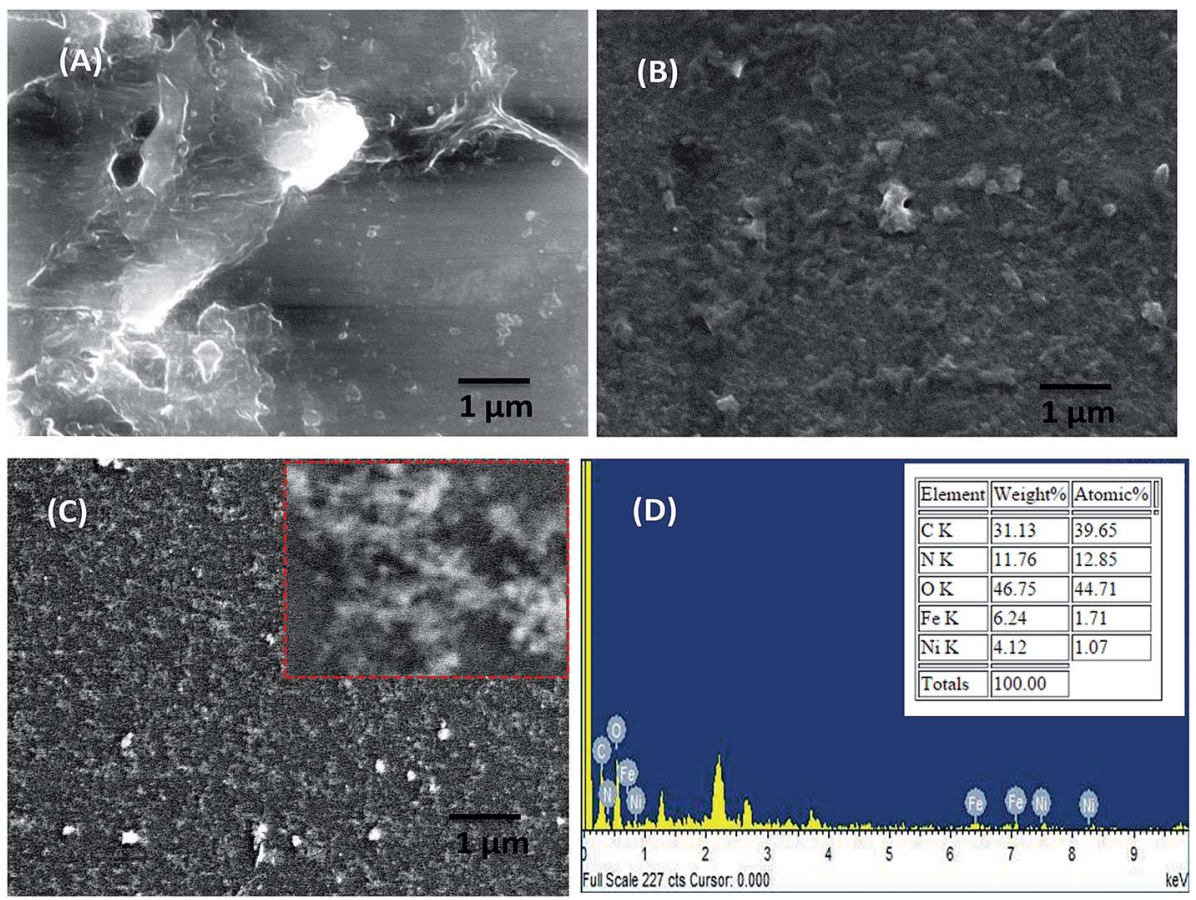

Fig. $4 \mathrm{SEM}$ images of (A) GO/ch/ITO electrode and (B) GO/NiF/ch/ITO electrode (C) pDNA/GO/NiF/ch/ITO bioelectrode, (D) EDX analysis of $\mathrm{GO} / \mathrm{NiF} / \mathrm{ch}$ nanocomposite. 
may be due to deformation of $\mathrm{O}-\mathrm{H}$, the peak at $1355 \mathrm{~cm}^{-1}$ attributes to vibration of $\mathrm{C}-\mathrm{O}$ (epoxy). A peak was observed at $971 \mathrm{~cm}^{-1}$ which attributes to vibration of C-O (alkoxy). ${ }^{37}$ Fig. 5(iii) shows the FT-IR spectrum of chitosan. A broad band observed at $3396 \mathrm{~cm}^{-1}$ may be assigned to $\mathrm{N}-\mathrm{H}$ stretching vibrations in amide or amine groups while the peak at 1637 $\mathrm{cm}^{-1}$ is due to amide I group (C-O stretching along with $\mathrm{N}-\mathrm{H}$ deformation mode), $1380 \mathrm{~cm}^{-1}$ peak is assigned to $\mathrm{COO}^{-}$group in carboxylic acid salt and the peak at 1085 is assigned to the stretching vibration mode of the hydroxyl group. ${ }^{38}$ Fig. 5(iv) shows the FT-IR spectrum of $\mathrm{NiFe}_{2} \mathrm{O}_{4}$ nanoparticles. A peak observed at $607 \mathrm{~cm}^{-1}$ may be due to intrinsic stretching vibrations of the metal at the tetrahedral site $(\mathrm{Fe}-\mathrm{O})$, whereas the band at $455 \mathrm{~cm}^{-1}$ is attributed to octahedral metal stretching (Ni-O). ${ }^{39}$ A peak was also observed at $3399 \mathrm{~cm}^{-1}$ which may be due to characteristic hydroxyl group $(\mathrm{O}-\mathrm{H})$ adsorbed onto the surface of $\mathrm{NiFe}_{2} \mathrm{O}_{4}$. In the spectra of $\mathrm{GO} / \mathrm{NiF} / \mathrm{ch}$ nanocomposite Fig. 5(i) it can be observed that the vibration bands have shifted after the interaction of the nanoparticles and chitosan with graphene confirming the formation of nanocomposite. For example, $-\mathrm{OH}$ vibration peak shifted to $3178 \mathrm{~cm}^{-1}$, peaks due to amide II shifted to $1647 \mathrm{~cm}^{-1}, \mathrm{C}-\mathrm{O}$ vibration peak shifted to 921 $\mathrm{cm}^{-1}$ while the peaks due to $\mathrm{Fe}-\mathrm{O}$ stretching and $\mathrm{Ni}-\mathrm{O}$ stretching has shifted to $643 \mathrm{~cm}^{-1}$ and $521 \mathrm{~cm}^{-1}$ respectively.

\subsection{Raman analysis}

Raman spectroscopy is one of the most sensitive and informative techniques to characterize disorder in $\mathrm{sp}^{2}$ carbon materials. $\mathrm{D}$ band arises from $\mathrm{sp}^{3}$-hybridized carbon and is an indication of disorder in the structure while the $\mathrm{G}$ band arises from the zone center $\mathrm{E}_{2 \mathrm{~g}}$ mode, which corresponds to the ordered $\mathrm{sp}^{2}$ bonded carbon. ${ }^{40}$ Fig. $\mathrm{S} 1(\mathrm{~A}) \dagger$ shows the spectra of GO, in which a peak is observed at $1590 \mathrm{~cm}^{-1}$ which corresponds to D band while the peak observed at $1353 \mathrm{~cm}^{-1}$ corresponds to $\mathrm{G}$ band. In the spectra of $\mathrm{GO} / \mathrm{NiF} / \mathrm{ch}$ nanocomposite (Fig. S1(B) $\dagger$ ), it is observed that the composite contains both the $\mathrm{G}$ and $\mathrm{D}$ bands but the $\mathrm{G}$ band has shifted to $1341 \mathrm{~cm}^{-1}$ while $\mathrm{D}$ band shifted to $1587 \mathrm{~cm}^{-1}$ which indicates that the main structure of graphene is conserved even in the composite. Apart from this, some additional peaks appeared in the range of $200-1000 \mathrm{~cm}^{-1}$ in the

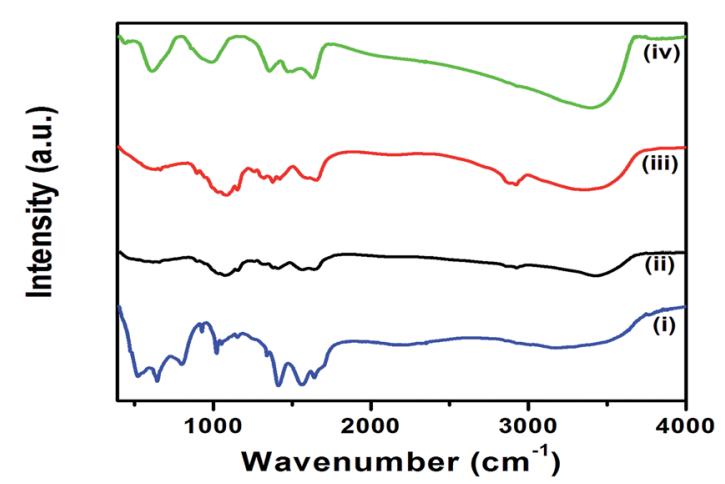

Fig. 5 FT-IR spectra of (i) GO/NiF/ch nanocomposite, (ii) GO, (iii) chitosan, (iv) $\mathrm{NiFe}_{2} \mathrm{O}_{4}$ nanoparticles. spectra of composite, which may be due to crystalline $\mathrm{NiFe}_{2} \mathrm{O}_{4} \cdot{ }^{39}$ Raman spectra can be used to characterize the level of disorder in graphene and average size of the $\mathrm{sp}^{2}$ domains by using the ratio of peak intensities $I_{\mathrm{D}} / I_{\mathrm{G}}$. As the degree of disorderness increases in graphene, the Raman intensity decreases for the $\mathrm{G}$ band; hence the ratio $I_{\mathrm{D}} / I_{\mathrm{G}}$ is increased. In our case, the $I_{\mathrm{D}} / I_{\mathrm{G}}$ value for GO is 0.86 and for composite, it is 0.99 . Increase in $I_{\mathrm{D}} /$ $I_{\mathrm{G}}$ value indicates that disorderness is increased which may be due to decrease in the average size of the $\mathrm{sp}^{2}$ domains present in GO after interacting with chitosan and nanoparticles. ${ }^{30}$

\subsection{Thermal gravimetric analysis (TGA)}

TGA is a simple analytical technique that measures the weight loss of a material as a function of temperature. As the samples are heated, they lose weight from a simple process such as drying, or from chemical reactions or decompositions that liberate gases. Fig. S2(i) $\dagger$ shows the TGA graph of the GO/ chitosan composite. In the first step, weight loss $(\sim 7 \%)$ is in the temperature range $33{ }^{\circ} \mathrm{C}$ to $72{ }^{\circ} \mathrm{C}$ which may be due to loss of moisture from the sample. $93 \%$ mass is retained here. $2^{\text {nd }}$ step shows the major weight loss $(\sim 13 \%)$ in the temperature range of $108{ }^{\circ} \mathrm{C}$ to $327^{\circ} \mathrm{C}$ which reveals the decomposition of functional groups (labile oxygen groups such as carboxylic, anhydride, or lactones groups), on the surface of the GO sheets. Residual weight is $80 \% .3^{\text {rd }}$ step shows decomposition above $320{ }^{\circ} \mathrm{C}$ which is attributed to the removal of more stable oxygen functionalities (such as phenol, carbonyl, quinone). Fig. S2(ii)† shows the TGA of $\mathrm{GO} / \mathrm{NiF} / \mathrm{ch}$ composite. It was found that due to introduction of $\mathrm{NiFe}_{2} \mathrm{O}_{4}$, thermal stability is slightly reduced.

\subsection{Electrochemical characterization}

It was found that the electron transfer rate of $\mathrm{Fe}^{3+/ 2+}$ on RGO is much higher than that on a glassy carbon electrode (GCE) due to the unique electronic structure of RGO. Due to its favorable electron mobility and unique surface properties, such as oneatom thickness and high specific surface area, GO can accommodate the active species and facilitate their electron transfer at electrode. Electron transfer can be enhanced also because small graphene flakes are able to provide direct electrical wiring between the electrode and the redox active centers. ${ }^{\mathbf{4 1}}$ Electron transfer mechanism is explained by heterogeneous rate transfer which depends upon an important parameter of an electrode material which is its electronic properties, namely, the density of electronic states (DOS) as discussed in the literature. ${ }^{42}$ Briefly a higher DOS increases the possibility that an electron of the correct energy is available for the electrode to transfer to an electro-active species. The DOS at graphitic materials can be increased through disorder such that electroactive species exhibit increasing electron transfer rates but by varying amounts; in terms of outer-sphere electron transfer systems, disorder increases the rate by modifying the electronic structure of the carbon while for inner-sphere systems, specific surface interactions also contribute.

3.7.1 Cyclic voltammetry studies. Cyclic voltammetry was performed to study various kinetic parameters of $\mathrm{GO} / \mathrm{NiF} / \mathrm{ch} /$ ITO electrode (Fig. 6A) and pDNA/GO/NiF/ch/ITO bioelectrode 
(Fig. 6B) at various potential scan rates in the range $10-300 \mathrm{mV} \mathrm{s}^{-1}$. It is observed that with increase in scan rate, anodic peak current $\left(I_{\mathrm{pa}}\right)$ and cathodic peak current $\left(I_{\mathrm{pc}}\right)$ increases and also peak separation $\left(\Delta E_{\mathrm{p}}\right)$ increases. The redox peak currents $\left(I_{\mathrm{pa}}\right.$ and $\left.I_{\mathrm{pc}}\right)$ decrease and peak separation potential $\left(\Delta E_{\mathrm{p}}\right)$ increases for $\mathrm{pDNA} / \mathrm{GO} / \mathrm{NiF} / \mathrm{ch} / \mathrm{ITO}$ as compared to $\mathrm{GO} / \mathrm{NiF} / \mathrm{ch} / \mathrm{ITO}$. It is due to the reason that the negatively charged probe DNA block the electron transfer of $\left[\mathrm{Fe}(\mathrm{CN})_{6}\right]^{3-/ 4-}$, resulting in the remarkable decrease of peak current (Fig. S3 $\dagger$ ).

Inset (i) to Fig. 6 describes the plot of peak currents $\left(I_{\mathrm{p}}\right)$ as a function of square root of scan rate $\left(\nu^{1 / 2}\right)$ which exhibits straight line behavior (with correlation coefficient, $R^{2}=0.995$ ) as shown by the eqn (1) and (2) for $\mathrm{GO} / \mathrm{NiF} / \mathrm{ch}$ ) electrode while (3) and (4) for $\mathrm{pDNA} / \mathrm{GO} / \mathrm{NiF} / \mathrm{ch}$ bioelectrode respectively. These results suggest that the electrochemical process is diffusion controlled.

$$
\begin{gathered}
I_{\mathrm{pa}(\mathrm{GO} / \mathrm{NiF} / \mathrm{ch})}=1.211 \times 10^{-4} \times \nu^{1 / 2}+7.228 \times 10^{-5} \\
I_{\mathrm{pc}(\mathrm{GO} / \mathrm{NiF} / \mathrm{ch})}=-1.920 \times 10^{-4} \times \nu^{1 / 2}-4.771 \times 10^{-5} \\
I_{\mathrm{pa}(\mathrm{pDNA} / \mathrm{GO} / \mathrm{NiF} / \mathrm{ch})}=6.423 \times 10^{-5} \times \nu^{1 / 2}+1.1548 \times 10^{-4} \\
I_{\mathrm{pc}(\mathrm{pDNA} / \mathrm{GO} / \mathrm{NiF} / \mathrm{ch})}=-3.668 \times 10^{-5} \times \nu^{1 / 2}-2.382 \times 10^{-5}
\end{gathered}
$$

The diffusion coefficient ' $D$ ' has been calculated using Randal-Sevcik eqn (5)

$$
I_{\mathrm{p}}=\left(2.69 \times 10^{5}\right) \alpha^{1 / 2} n^{3 / 2} A D^{1 / 2} C \nu^{1 / 2}
$$

and was found to be $6.32 \times 10^{-4} \mathrm{~cm}^{2} \mathrm{~s}^{-1}$ and $1.02 \times 10^{-6} \mathrm{~cm}^{2} \mathrm{~s}^{-1}$ for $\mathrm{GO} / \mathrm{NiF} / \mathrm{ch}$ electrode and $\mathrm{pDNA} / \mathrm{GO} / \mathrm{NiF} / \mathrm{ch}$ bioelectrode respectively where $I_{\mathrm{p}}$ is the peak current, $\nu$ is scan rate in $\mathrm{V} \mathrm{s}^{-1}$ $\left(30 \mathrm{mV}^{-1}\right), A$ is area of film in $\mathrm{cm}^{2}\left(0.25 \mathrm{~cm}^{2}\right), \mathrm{C}$ is the bulk concentration $\left(5 \mathrm{mM}\right.$ for $\left.\left[\mathrm{Fe}(\mathrm{CN})_{6}\right]^{3-/ 4}\right), n$ is number of electron transfer per molecule in oxidation process (here $n=1$ )]. Inset (ii) to Fig. 6 shows plot of peak potential versus log of scan rate and it can be seen that both anodic $\left(E_{\mathrm{a}}\right)$ and cathodic peak $\left(E_{\mathrm{c}}\right)$ potentials increases linearly as function of scan rate following the eqn (6) and (7) for $\mathrm{GO} / \mathrm{NiF} / \mathrm{ch}$ electrode while (8) and (9) for $\mathrm{pDNA} / \mathrm{GO} / \mathrm{NiF} / \mathrm{ch}$ bioelectrode respectively.

$$
\begin{gathered}
E_{\mathrm{pa}(\mathrm{GO} / \mathrm{NiF} / \mathrm{ch})}=0.0573 \log \nu+0.1449 \\
E_{\mathrm{pc}(\mathrm{GO} / \mathrm{NiF} / \mathrm{ch})}=-0.0408 \log \nu+0.1426 \\
E_{\mathrm{pa}(\mathrm{pDNA} / \mathrm{GO} / \mathrm{NiF} / \mathrm{ch})}=0.08186 \log \nu+0.14521 \\
E_{\mathrm{pc}(\mathrm{pDNA} / \mathrm{GO} / \mathrm{NiF} / \mathrm{ch})}=-0.07401 \log \nu+0.16746
\end{gathered}
$$

The surface coverage (T) of the electroactive substance could be calculated according to the Laviron equation. ${ }^{43}$

$$
I_{\mathrm{p}}=n^{2} F^{2} A T \nu(4 R T)^{-1}=n F Q \nu(4 R T)^{-1}
$$

Taking the average of both the cathodic and anodic results, $\mathrm{T}$ is found to be $6.0489 \times 10^{-8} \mathrm{~mol} \mathrm{~cm}{ }^{-2}$. The electrochemical kinetic parameters could also be calculated for a cyclic voltammetric system using the Laviron's eqn (11)-(13). ${ }^{44}$

$$
\begin{gathered}
E_{\mathrm{pa}}=E^{0^{\prime}}+(2.3 R T / 1-\alpha) n F \log \nu \\
E_{\mathrm{pc}}=E^{0}-2.3 R T / \alpha n F \log \nu
\end{gathered}
$$

$\log k_{\mathrm{s}}=\alpha \log (1-\alpha)+(1-\alpha) \log \alpha-\log (R T / n F v)$

$$
-\alpha(1-\alpha) n F \Delta E_{\mathrm{p}} / 2.3 R T
$$

where $\alpha$ is the charge transfer coefficient, $k_{\mathrm{s}}$ the electrode reaction constant, $\nu$ the scan rate, $R$ the gas constant, $F$ the Faraday constant, $T$ the absolute temperature, $\Delta E_{\mathrm{p}}$ the peak-topeak separation and $E^{0^{\prime}}$ the apparent formal potential. From eqn (11)-(13) $\alpha$ and $k_{\mathrm{s}}$ was calculated and found to be 0.45 and $0.925 \mathrm{~s}^{-1}$ for $\mathrm{GO} / \mathrm{NiF} / \mathrm{ch}$ electrode and 0.5 and $0.863 \mathrm{~s}^{-1}$ for $\mathrm{pDNA} / \mathrm{GO} / \mathrm{NiF} / \mathrm{ch}$ bioelectrode respectively.

Based on the above result, it can be concluded that the prepared bioelectrode has good electron transfer kinetics. Due to the synergistic effect of large surface area of graphene and $\mathrm{NiFe}_{2} \mathrm{O}_{4}$ nanoparticles, the apparent electrode area is improved
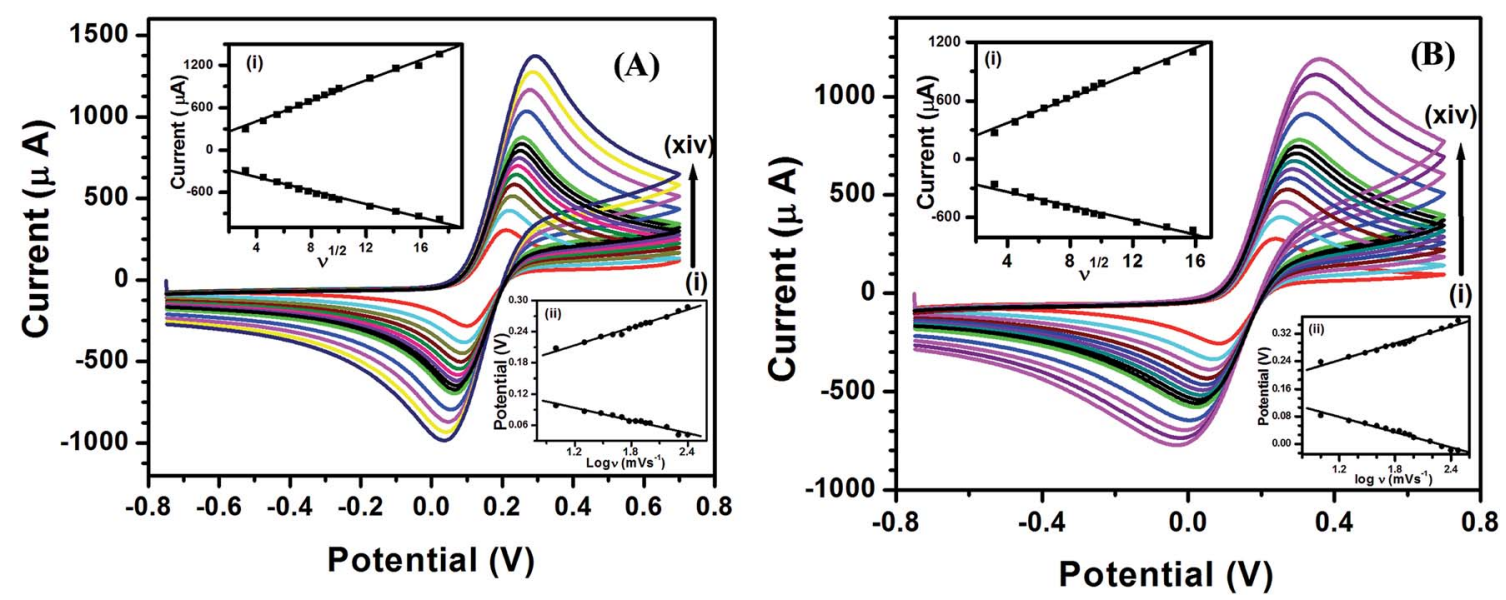

Fig. 6 Cyclic voltammetric variation of (A) GO/NiF/ch/ITO electrode and (B) pDNA/GO/NiF/ch/ITO electrode with scan rate in PBS (100 mM, pH $7.4,0.9 \% \mathrm{NaCl}$ ) solution containing $5 \mathrm{mM}\left[\mathrm{Fe}(\mathrm{CN})_{6}\right]^{3-14-}$. Inset: shows the variation of (i) current with square root of scan rate and (ii) potential with log of scan rate. 
greatly, hence good electron transfer kinetics is observed on the modified electrodes.

\subsection{Electrochemical response studies}

3.8.1 Response studies of the pDNA/GO/NiF/ch. Electrochemical response studies were carried out using DPV where methylene blue $(\mathrm{MB})$ is used as hybridization indicator $(20 \mu \mathrm{M})$ in 0.05 M PBS, pH 7.0. MB is an organic dye which could bind specifically to the free guanine bases on DNA molecules. Therefore it has a strong affinity for free single strand DNA as compared to double stranded DNA. ${ }^{45}$

Fig. 7A shows the DPV response of the pDNA/GO/NiF/ch bioelectrodes after hybridization with complementary target by varying concentration of complementary DNA ranging from $10^{-16}$ to $10^{-6} \mathrm{M}$ at $25{ }^{\circ} \mathrm{C}$ in $20 \mu \mathrm{M} \mathrm{MB}$. It is observed that hybridization has taken place in $60 \mathrm{~s}$ (inset to Fig. 7B). It could be observed that there is decrease in MB oxidation current with increasing concentrations of complementary DNA used for hybridization which may be due to hindrance of the MB: guanine interaction driven by duplex formation. ${ }^{46}$ The peak current vary logarithmically with DNA concentration in the range $10^{-16}$ to $10^{-6} \mathrm{M}$ (Fig. $7 \mathrm{~B}$ ), following the equation;

$$
I_{\mathrm{dsDNA}}=-6.22453 \times 10^{-8}+1.70975 \times 10^{-7} \log [\mathrm{cDNA}]
$$

The detection limit was calculated using the formula $3 \sigma /$ sensitivity and found to be $1.0 \times 10^{-16} \mathrm{M}$. This increase in the sensitivity is due to the excellent electrical conductivity of the fabricated matrix.

3.8.2 Selectivity of the bioelectrode. The selectivity of DNA sensor was investigated based on the oxidation current of $\mathrm{MB}$ using single-base mismatched, non-complementary, and complementary DNA sequence (Fig. S4 $\uparrow$ ). When the GO/NiF/ch/ITO electrode was treated with non-complementary oligonucleotide sequence, there was negligible change in peak current Fig. S4(i) $\dagger$ with respect to probe DNA which is due to interaction of DNA and $\mathrm{MB}$ as free guanine are available indicating that no hybrid is formed. However, it is observed that there is a large increase in the MB oxidation peak current in DPV for the probe DNA modified electrode as indicated in Fig. S4(ii). $\dagger$ After incubation with complementary oligonucleotide sequence, peak current is decreased sharply. Fig. S4(iv) $\dagger$ which may be due to the unavailability of free guanine bases which indicates that hybridization has occurred. Similarly, after treating with one base mismatch sequence, Fig. S4(iii), $\dagger$ there was decrease in current with respect to pDNA due to less availability of free guanine. ${ }^{47}$

3.8.3 Specificity of the bioelectrode. The specificity of the $\mathrm{pDNA} / \mathrm{GO} / \mathrm{NiF} / \mathrm{ch}$ bioelectrode has been studied using culture DNA samples of E. coli, S. typhimurium, N. meningitidis and $K$. pneumonia and the results are shown in Fig. S5. $\dagger$ It could be observed that when pDNA/GO/NiF/ch bioelectrode was incubated with culture samples of $E$. coli, change in current is negligible with respect to pDNA revealing that the culture sample of $E$. coli gives almost same response as pDNA which implies that the hybridization has taken place. However, when the bioelectrode was treated with DNA of other water borne pathogens, a large increase in the MB oxidization peak current is observed in DPV with respect to complementary DNA. This is due to the fact that hybridization has not taken place on pDNA/ $\mathrm{GO} / \mathrm{NiF} / \mathrm{ch}$ bioelectrode. These results reveal that pDNA/GO/ $\mathrm{NiF} / \mathrm{ch}$ bioelectrode are highly specific for the detection of $E$. coli.

3.8.4 Stability and regeneration of genosensor. The storage stability of the genosensor was tested by keeping the pDNA/GO/ $\mathrm{NiF} / \mathrm{ch}$ bioelectrode in a refrigerator $\left(4^{\circ} \mathrm{C}\right)$ and measuring its response towards complementary DNA of E. coli O157:H7 every five days (Fig. S6A $\dagger$ ). After thirty days, the impedimetric response of the sensor remains $90 \%$ of the initial value indicating that the genosensor had acceptable stability. Further, the regeneration step was carried out by immersing, hybridized pDNA/GO/NiF/ch bioelectrode in $5 \mathrm{~mL}$ of a $10 \mathrm{mM}$ Tris- $\mathrm{HCl}$ and
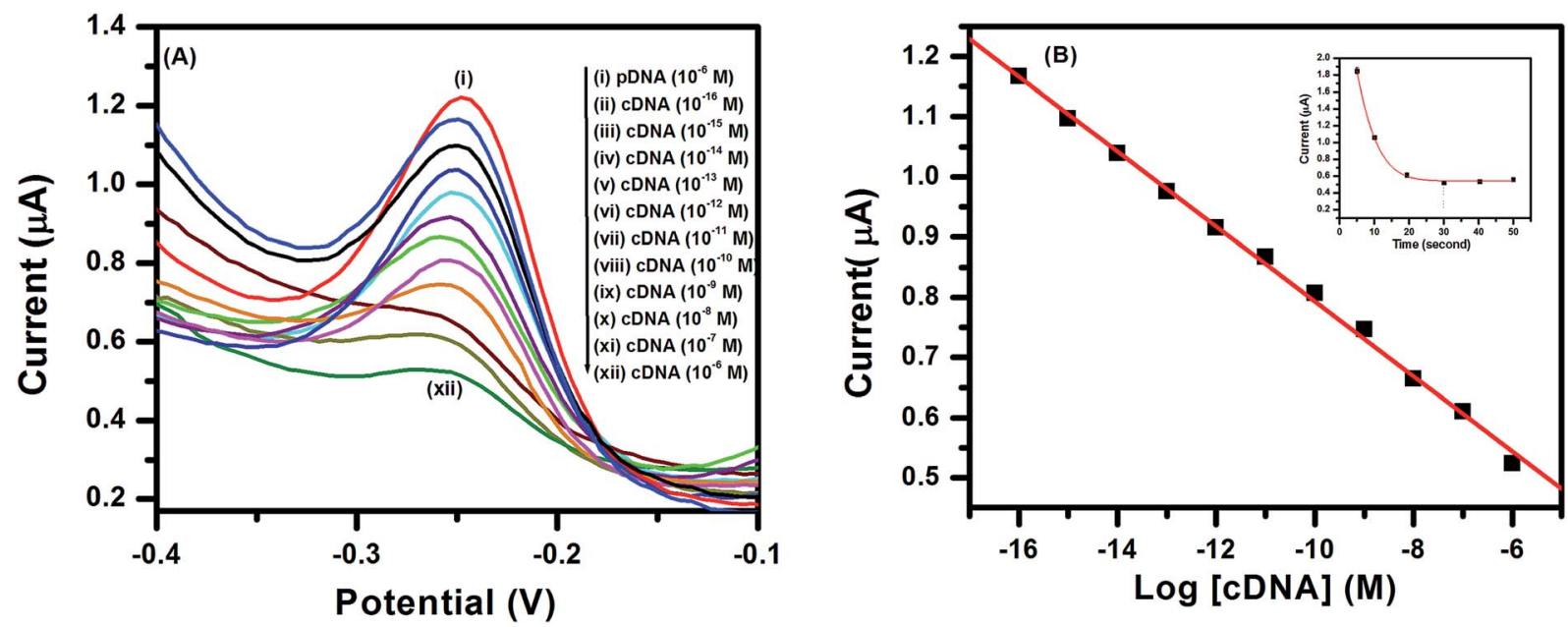

Fig. 7 (A) DPV response of $\mathrm{pDNA} / \mathrm{GO} / \mathrm{NiF} / \mathrm{ch} / \mathrm{ITO}$ bioelectrode as a function of complementary DNA concentration (10 ${ }^{-16}$ to $\left.10^{-6} \mathrm{M}\right)$ in PBS solution $(\mathrm{pH} 7.4)$ containing $5 \mathrm{mM}\left[\mathrm{Fe}(\mathrm{CN})_{6}\right]^{3-/ 4-}$. (B) Plot of the DPV response of pDNA/GO/NiF/ch/lTO bioelectrode vs. the logarithm of the target DNA concentrations with inset showing stability of pDNA/GO/NiF/ch/ITO bioelectrode as a function of time. 
$1 \mathrm{mM}$ EDTA buffer solution ( $\mathrm{pH} \mathrm{8.0)}$ at $100{ }^{\circ} \mathrm{C}$ for $5 \mathrm{~min}$, followed by cooling in an ice bath for $30 \mathrm{~min}$. Fig. $\mathrm{S} 6 \mathrm{~B} \uparrow$ shows that there is a gradual decrease in MB peak current with the increase of regeneration times. This may be due to the gradual shell off and denaturation of pDNA during continuous processing and cleaning. The results demonstrated that the proposed genosensor could be regenerated and used for at least 9 times with relative standard deviation of $11.2 \%$.

\section{Conclusions}

In the present work, graphene oxide, nickel ferrite-chitosannanocomposite was synthesized and electrophoretically deposited onto ITO coated glass substrate. Further, it was used for detection of specific DNA sequence of $E$. coli. It was observed that the prepared nanocomposite enhanced DNA detection and can successfully detect $E$. coli in the range of $10^{-6}$ to $10^{-16} \mathrm{M}$ using DPV technique. This fabricated biosensor is highly selective, sensitive and specific. Thus, the biosensor designed in this report could be an important tool for determining the presence of low concentrations of $E$. coli DNA in biological assays.

\section{Acknowledgements}

M. S. is thankful to DBT, India, Prof. Ranjan Singh (Department of Physics, B.H.U.) and Prof. O.N. Srivastava (Department of Physics, B.H.U.) C. M. Pandey acknowledges University Grant Commission, India for providing Dr D. S. Kothari Postdoctoral fellowship (No. F.4-2/2006 (BSR)/CH/14-15/0164). Thanks are due to Dr Seema Sood (AIIMS, New Delhi) for providing the bacterial culture samples Ms Shipra Solanki (NPL, New Delhi) and Prof. B. D. Malhotra (DTU, Delhi) for interesting discussion. The financial support received from DBT (Grant No. BT/PR1791/ MED/32/174/2011), India and UGC-UKIERI is gratefully acknowledged.

\section{References}

1 A. K. Deisingh and M. Thompson, J. Appl. Microbiol., 2004, 96, 419-429.

2 J. M. Rangel, P. H. Sparling, C. Crowe, P. M. Griffin and D. L. Swerdlow, Emerging Infect. Dis., 2005, 11, 603-609.

3 J. Tuttle, T. Gomez, M. P. Doyle, J. G. Wells, T. Zhao, R. V. Tauxe and P. M. Griffin, Epidemiol. Infect., 1999, 122, 185-192.

4 E. Berkenpas, P. Millard and M. Pereira da Cunha, Biosens. Bioelectron., 2006, 21, 2255-2262.

5 A. Rompré, P. Servais, J. Baudart, M.-R. de-Roubin and P. Laurent, J. Microbiol. Methods, 2002, 49, 31-54.

6 J. Devenish, B. Brooks, K. Perry, D. Milnes, T. Burke, D. McCabe, S. Duff and C. L. Lutze-Wallace, Clin. Diagn. Lab. Immunol., 2005, 12, 1261-1268.

7 S. D. Miszczycha, S. Ganet, L. Duniere, C. Rozand, E. Loukiadis and D. Thevenot-Sergentet, J. Food Prot., 2012, 75, 1373-1381.
8 J. L. Holland, L. Louie, A. E. Simor and M. Louie, J. Clin. Microbiol., 2000, 38, 4108-4113.

9 C. P. Gu, J. R. Huang, J. H. Wang, C. J. Wang, M. Q. Li and J. H. Liu, Anal. Lett., 2007, 40, 3159-3169.

10 M. Tak, V. Gupta and M. Tomar, Biosens. Bioelectron., 2014, 59, 200-207.

11 T. Yang, X. Guo, Y. Ma, Q. Li, L. Zhong and K. Jiao, Colloids Surf., B, 2013, 107, 257-261.

12 C. M. Pandey, R. Singh, G. Sumana, M. K. Pandey and B. D. Malhotra, Sens. Actuators, B, 2011, 151, 333-340.

13 J. Liu, J. Tang and J. J. Gooding, J. Mater. Chem., 2012, 22, 12435-12452.

14 M. J. Allen, V. C. Tung and R. B. Kaner, Chem. Rev., 2009, 110, 132-145.

15 A. Singh, G. Sinsinbar, M. Choudhary, V. Kumar, R. Pasricha, H. N. Verma, S. P. Singh and K. Arora, Sens. Actuators, B, 2013, 185, 675-684.

16 Y. Fang and E. Wang, Chem. Commun., 2013, 49, 9526-9539. 17 A. Benvidi, N. Rajabzadeh, M. Mazloum-Ardakani, M. M. Heidari and A. Mulchandani, Biosens. Bioelectron., 2014, 58, 145-152.

18 Y. Bo, H. Yang, Y. Hu, T. Yao and S. Huang, Electrochim. Acta, 2011, 56, 2676-2681.

19 N. Zainudin, A. R. Mohd Hairul, M. M. Yusoff, L. L. Tan and K. F. Chong, Anal. Methods, 2014, 6, 7935-7941.

20 L. Zeng, R. Wang, L. Zhu and J. Zhang, Colloids Surf., B, 2013, 110, 8-14.

21 W. Sun, Y. Zhang, X. Ju, G. Li, H. Gao and Z. Sun, Anal. Chim. Acta, 2012, 752, 39-44.

22 A. Shi, J. Wang, X. Han, X. Fang and Y. Zhang, Sens. Actuators, B, 2014, 200, 206-212.

23 H. Cai, Y. Wang, P. He and Y. Fang, Anal. Chim. Acta, 2002, 469, 165-172.

24 C. X. Xu, Q.-G. Zhai, Y.-J. Liu, K.-J. Huang, L. Lu and K.-X. Li, Anal. Bioanal. Chem., 2014, 406, 6943-6951.

25 T. D. Schladt, K. Schneider, H. Schild and W. Tremel, Dalton Trans., 2011, 6315-6343.

26 D. E. Zhang, X. J. Zhang, X. M. Ni, H. G. Zheng and D. D. Yang, J. Magn. Magn. Mater., 2005, 292, 79-82.

27 A. A. Ensafi, M. Jafari-Asl, B. Rezaei and A. R. Allafchian, Sens. Actuators, B, 2013, 177, 634-642.

28 A. A. Ensafi and A. R. Allafchian, Colloids Surf., B, 2013, 102, 687-693.

29 Z. Wang, X. Zhang, Y. Li, Z. Liu and Z. Hao, J. Mater. Chem. A, 2013, 1, 6393-6399.

30 A. Afkhami, H. Khoshsafar, H. Bagheri and T. Madrakian, Anal. Chim. Acta, 2014, 831, 50-59.

31 X. Kang, J. Wang, H. Wu, I. A. Aksay, J. Liu and Y. Lin, Biosens. Bioelectron., 2009, 25, 901-905.

32 K. Haubner, J. Murawski, P. Olk, L. M. Eng, C. Ziegler, B. Adolphi and E. Jaehne, ChemPhysChem, 2010, 11, 21312139.

33 I. Tiwari, M. Singh, C. M. Pandey and G. Sumana, Sens. Actuators, B, 2015, 206, 276-283.

34 D. Zhou and B.-H. Han, Adv. Funct. Mater., 2010, 20, 27172722. 
35 T. Jiang, Z. Zhang, Y. Zhou, Y. Liu, Z. Wang, H. Tong, X. Shen and Y. Wang, Biomacromolecules, 2010, 11, 1254-1260.

36 K. Li, J. Huang, G. Shi, W. Zhang and L. Jin, Anal. Lett., 2011, 44, 2559-2570.

37 F. He, J. Fan, D. Ma, L. Zhang, C. Leung and H. L. Chan, Carbon, 2010, 48, 3139-3144.

38 D. Han, T. Han, C. Shan, A. Ivaska and L. Niu, Electroanalysis, 2010, 22, 2001-2008.

39 M. Fu, Q. Jiao and Y. Zhao, J. Mater. Chem. A, 2013, 1, 55775586.

40 K. N. Kudin, B. Ozbas, H. C. Schniepp, R. K. Prud'homme, I. A. Aksay and R. Car, Nano Lett., 2007, 8, 36-41.
41 C.-P. Chen, W.-R. Luo, C.-N. Chen, S. M. Wu, S. Hsieh, C.-M. Chiang and T.-Y. Dong, Langmuir, 2013, 29, 3106-3115.

42 M. Pumera, Energy Environ. Sci., 2011, 4, 668-674.

43 H.-Y. Gu, A.-M. Yu and H.-Y. Chen, J. Electroanal. Chem., 2001, 516, 119-126.

$44 \mathrm{~W}$. Sun, Z. Zhai, D. Wang, S. Liu and K. Jiao, Bioelectrochemistry, 2009, 74, 295-300.

45 T. Tian, Z. Li and E.-C. Lee, Biosens. Bioelectron., 2014, 53, 336-339.

46 B. Liu, J. Hu and J. S. Foord, Electrochem. Commun., 2012, 19, 46-49.

47 W. Sun, X. Qi, Y. Chen, S. Liu and H. Gao, Talanta, 2011, 87, 106-112. 